\title{
Marguerite Séchehaye, una pionera en el estudio psicoanalítico de la esquizofrenia
}

RESUMEN: En este trabajo se analiza la trayectoria de Marguerite A. Séchehaye, pionera en el estudio de la esquizofrenia desde la óptica psicoanalítica.

PALABRAS CLAVES: Séchehaye, realización simbólica, esquizofrenia.
SUMMARY: This paper analyses the life and the work of Marguerite A. Séchehaye, a pioneer in the study of schizophrenia from a psychoanalytic perspective.

KEY WORDS: Séchehaye, symbolic realization, schizophrenia.

\section{Sobre su vida y actividades}

Marguerite A. Séchehaye (1887-1964), de soltera Burdet, nació en Suiza, donde fue educada según las normas y valores propios del credo protestante de su familia, descendiente de inmigrantes de los Cevenas (1). En la construcción de su personalidad, junto al carácter autoritario de su madre, destaca la naturaleza más afable e igualitaria de su progenitor, en quien halló mayor empatía que en su figura materna (2). Como otras jóvenes de su generación, asistió a una escuela secundaria exclusiva para chicas, en donde se graduó en literatura y pedagogía, y en la que, fruto de los cánones y convenciones imperantes en su época, la coeducación como modelo educativo alternativo aún no había sido plenamente aceptado socialmente.

Se matriculó en la universidad de Ginebra, donde se interesó por la obra de Ferdinand de Saussure (1857-1913), que ejercería influencia intelectual en la conceptualización lacaniana. Paralelamente, con 19 años, se casará con Albert Séchehaye (1870-1946), alumno aventajado de aquel lingüista (1). Asimismo, alimentando su curiosidad intelectual, ella estudió psicología y orientación profesional en el Instituto Rousseau, fundado por Édouard Claparède (1873-1940), de quien tras graduarse pasó a ser ayudante, pero abriendo a la vez una consulta como psicóloga. De esa época data también su contacto inicial con el psicoanálisis clásico, fruto casual de la amistad que a ella y a su esposo Albert les unía con el analista Raymond de Saussure (1884-1971), quien, según Louisa Séchehaye-Duess (19122002), hija adoptiva del matrimonio Séchehaye, le sugirió a su madre que se analizara, a lo que ésta se opuso, al juzgar que el saber psicoanalítico confería gran énfasis a la sexualidad, lo que atentaba contra sus creencias religiosas. De Saussure le argumentó que cómo podía ella conceptuar la terapia freudiana sin haber antes experimentado un análisis, así que ésta decidió someterse a tratamiento psicoanalí- 
tico, que inició al día siguiente, alrededor de 1927-1928, y duró unos seis meses (3). De acuerdo con sus propias reacciones emocionales, analizadas retrospectivamente, tal experiencia al parecer ni le resultó seria ni tuvo gran resonancia en su universo afectivo (2). Con todo, de Saussure le aconsejó iniciar su práctica analítica, cuyos primeros casos él supervisaría, para después encargarse ella en solitario de tales pacientes. Paralelamente, durante la década de 1930, en el hogar de los Saussure y del matrimonio Séchehaye, polemizaban analistas como Charles Odier (1886-1954), H. Flournoy (1881-1956), G. Richard y G. Dubal (1909-1993), quienes -a excepción de S. Spielrein (1885-1941 ó 1942) y Charles Baudouin (18931963)-, integraban el primer grupo analítico de Ginebra. De esos encuentros, Louisa Séchehaye-Duess refiere la influencia de su madre, quien era capaz sin pudor alguno de afirmar su ignorancia ante ciertas cuestiones allí planteadas.

Asimismo, junto a la reflexiva lectura de las obras de S. Freud (1856-1939) y J. Piaget (1896-1980), entre las dos Guerras Mundiales, Séchehaye favoreció la consolidación y expansión del movimiento psicoanalítico suizo, contactando para ello con figuras señeras como M. Klein (1882-1960), D. W. Winnicott (18961971), A. Freud (1895-1982) y R. Spitz (1887-1974), fruto de lo cual fue posiblemente germinando un método psicoterapéutico que, sustentado en la realización simbólica, serviría para el abordaje y tratamiento de la esquizofrenia; tales ideas se hallan en La realización simbólica (1947). En 1950, vería también la luz su Diario de una esquizofrénica, en el que, junto a los comentarios clínicos de Séchehaye, se recogía el testimonio personal de su paciente (Renée), de nombre real Louisa Duess; ella la adoptó, y como su madre adoptiva Renée se haría también analista.

Lo interesante del último trabajo es la relevancia que, sin pretenderlo, supuso para los investigadores de la enfermedad mental, y de la esquizofrenia en particular, en los sesenta, cuando se alzaron voces críticas que cuestionaban el hasta entonces estatuto de la locura (4). Planteaban como modelo alternativo la antipsiquiatría, según la cual se hacía factible que los locos expresaran por sí mismos la historia de sus casos, soslayando así la nosografía y patografías del saber psiquiátrico imperantes. Un año más tarde, durante el curso académico 1951-52, en la universidad de Zúrich, ayudada por su hija, Marguerite, impartió una serie de conferencias a los médicos del hospital cantonal de esa ciudad, conocido como Burghölzli, en las que se inspiró para su Psicoterapia de la esquizofrenia (5), de 1954; el título fue alterado en su homóloga inglesa de 1956, Una nueva psicoterapia para la esquizofrenia (6), así que parece sugerir una intervención psicoterapéutica más ambiciosa que la referida. Entre sus contenidos, además del método curativo, se muestra el examen de algunos sujetos esquizofrénicos, resultando por ello muy didáctico. 
HISTORIA DE LA PSIQUIATRÍA

El II Congreso Internacional de Psiquiatría tuvo lugar en Zúrich (1 al 7- IX1957). Se organizó en torno al estatuto de nuestro conocimiento acerca del grupo de las esquizofrenias, Séchehaye dio la conferencia «Teoría psicoanalítica de la esquizofrenia» (7), de la que gracias al Dr. Kaspar Weber (8), actual archivista de la Sociedad Psicoanalítica Suiza, disponemos de copia casi completa (se han perdido sus páginas finales); ésta, al revisar los archivos de la Sociedad halló anexa una carta de la antigua archivera, Mme. de Sangy, quien expresaba que si bien a Séchehaye no le satisfizo el final de su conferencia, juzgaba que debía de haberse publicado. De tal disertación destaca el recorrido histórico exhaustivo que realiza desde el saber psiquiátrico y psicoanalítico de la esquizofrenia, de la que defiende su psicogénesis, al no existir datos precisos de su etiología biológica, el resto lo dedica a la filosofía existencial y la realización simbólica; concluye que aún falta mucho por investigar.

En su labor magisterial, sobresale la de su discipulado, y cabe mencionar a Marguerite Wolf, enfermera psiquiátrica, que, alrededor de 1952, a causa de un grave deterioro en la salud mental de Walter Federn -uno de los vástagos de Paul Federn (1871-1950) que ya en 1926 había sido diagnosticado de esquizofrenia por éste-, aplicó, junto a una psiquiatra, un ama de llaves y Ernst, hermano de Walter, las enseñanzas de Séchehaye. Como resultado de ello, según nos escribe Ernst el 3-II-2000, su hermano quedó completamente restablecido (9). Ms. Wolf le había sido presentada a P. Federn a finales de 1940 por el Dr. Heinrich Meng (18871975), uno de sus analizados y después analista, siendo también digno reseñar de la semblanza de la Wolf el trabajo con John N. Rosen (1902-1983) en el hospital estatal de Boston (10). El primer reconocimiento público a la trayectoria de Séchehaye se produjo en 1962, cuando un grupo de psiquiatras la honraron otorgándole una medalla de oro en Milán. Recibió un segundo homenaje en 1964, el día de año nuevo, en el que en la Sociedad Psicoanalítica Suiza, y ante los allí congregados, el Dr. Christian Müller destacó la impronta que había dejado en jóvenes psiquiatras y psicoanalistas suizos (2); seis meses después, el 1 de junio de 1964, Séchehaye falleció.

\section{La realización simbólica, alternativa al tratamiento clásico de la esquizofrenia}

En 1947, en el cuaderno especial n. ${ }^{\circ} 12$ de la Revista Suiza de Psicología y de Psicología aplicada, aparecía La realización simbólica (Nuevo método de psicoterapia aplicado a un caso de esquizofrenia), como método psicoterapéutico para abordar y tratar la esquizofrenia. O, como bien sugiere Odier (11), del método de la satisfacción simbólica de las necesidades fundamentales, afectivas, que, al no haber sido gratificadas, se han mantenido siempre a la espera de ser colma- 
das, satisfaciéndose la enferma ficticia e indirectamente de la psicosis y de las ilusiones de los sentidos para alcanzar tales anhelos interiores. De la esencia de tal técnica terapéutica, fruto clínico de Séchehaye, referimos lo expresado por $R$. de S. (seguramente Raymond de Saussure), que, en el periódico de Ginebra, el 9-VII-1964, rendía un cálido homenaje a Marguerite Séchehaye-Burdet; junto a una breve semblanza afirmaba de la realización simbólica: «Este método consiste en hacer participar al enfermo de la relación terapéutica, de un modo presimbólico y mágico, proponiéndole símbolos que compensen sus necesidades infantiles frustradas. Lejos de exigir un esfuerzo de adaptación al enfermo a la situación conflictiva, le propone otra realidad más dulce, más soportable, como primera etapa a superar. Y es que, al igual que una madre por su hijo, ella se esfuerza por adaptarse a las necesidades del enfermo, adivinándolas, pues ni él mismo consigue expresarlas, para finalmente realizarlas simbólicamente» (12). Guiada por tales presupuestos, Séchehaye dirigió sus esfuerzos a que su paciente vivenciara ciertas satisfacciones reales y concretas, aunque bajo formas infantiles (esto es, inmediatas), sustituyendo así la satisfacción psicótica ciega por otra de naturaleza plena y consciente. Y así, según Odier (11), fue curada una mujer esquizofrénica adulta e inteligente. Como complemento, a poco aparecía el Diario de una esquizofrénica (1950), donde, además de las propias vivencias emocionales de la paciente, se mostraban las interpretaciones formuladas por Séchehaye acerca de la génesis y desarrollo posterior de la personalidad, como de la desintegración y reconstrucción del yo, nutriéndose de las teorías freudiana y piagetiana (13).

En la introducción a La realización simbólica, expresa el especial interés que reviste el caso clínico abordado, desde que éste no parece ser un conflicto intrapsíquico entre el yo y el superyó, sino un trastorno primitivo vinculado a la génesis del yo (14). Y es que, examinada al menos por quince psiquiatras, aún variando la etiqueta diagnóstica (esquizofrenia, demencia precoz, esquizofrenia naciente con síntomas neuróticos, etc.), la enferma (Renée) fue desahuciada de toda intervención clínica. Sólo una adaptación de la terapia freudiana dio aparentes resultados terapéuticos. Además, para educar la atención de la paciente, afecta entre otros síntomas de extrañamiento perceptivo, Séchehaye incluyó otros ejercicios, en un intento de reconexión con la realidad externa de la que aquélla había huido a otra interna. Tales intervenciones clínicas atentan sin duda contra la regla de la neutralidad terapéutica, lo que, para M-A. Séchehaye -a diferencia de J. N. Rosen (4), que opta por la violencia protectora y la fractura psíquica, bajo las que acoge un tipo de intervención directa, con un método muy directivo, mediante el que se introduce por la fuerza en el mundo del paciente, que debe rendirle cuentas-, aquélla aboga por usar frente al analizado lo que denomina fibra maternal. Tal rol, a nuestro entender, se asemeja al postulado por Winnicott acerca del analista en el imaginario del paciente como una madre suficientemente buena. 
HISTORIA DE LA PSIQUIATRÍA

A raíz de las circunstancias familiares contadas en la anamnesia de Renée, que Séchehaye recopiló de su madre y de sus hermanos, todo adquiere más relieve cuando se evidencia su condición de hija no deseada y el infeliz matrimonio de sus progenitores, así como la delicada situación económica de su familia. Unido a ello, Renée debe soportar los reproches y acusación materna de no quererla suficiente, lo que la aboca a una severa angustia, sentimiento de culpa y agresión inconsciente, a la par que a rituales y a un desenfrenado onanismo, circunscrito a sensaciones espasmódicas sin contacto en la zona genital, además de ocasionales ilusiones ópticas vinculadas a la muerte, los cementerios y la religión (14). Enviada a un sanatorio en la montaña, dado su estado de salud, por decisión materna y pese a lo prescrito, Renée abandona tal institución, a la que luego retorna, dado su empeoramiento psíquico. Entonces se la trata con métodos sugestivos e hipnóticos, que, aunque fallidos, sitúan en la temprana infancia el germen de sus alteraciones psico-(pato)lógicas presentes. Es así como -ante el imparable agravamiento psíquico de Renée - es derivada a Séchehaye, indicándole tal médico que la paciente está en las primeras fases de una esquizofrenia, que duda poder ayudarla, al estar al borde de una desintegración mental.

En el proceso psicoterapéutico, que comienza alrededor de julio de 1930, se advierte que un año después de su inicio, la esquizofrenia sigue su curso inexorable. Parece que la terapia es ineficaz, aun cuando resulta positivo que Renée trabaje en una oficina. Movida tal vez por ello, a finales de 1933, Séchehaye, altera el encuadre de la terapia freudiana; desarrolla las sesiones cara a cara, y no al modo convencional, en que el analizado tumbado carece de la retroalimentación facial y corporal proporcionada por su analista. Asimismo, la drástica reducción de la ingesta de Renée a unos pocos alimentos, entre ellos espinacas y manzanas, es usado por Séchehaye para fortalecer el vínculo terapéutico, dada la carga simbólica asociada que tal fruta tiene para su analizada con la frustración y rabia interna vivenciada hacia el pecho materno. Un objeto parcial representativo de la madre, incapaz de satisfacer las necesidades nutricias y afectivas del lactante, ahora ya un adulto. La ingesta gradual de trozos de manzana se convierte en un símbolo gratificante y sustitutivo de la leche real, y de la posibilidad de vivenciar una emoción correctiva, en donde Séchehaye se torna la madre nutricia biológica y afectiva, al contrario que la progenitora real de Renée. Pues, dado su fuerte sentimiento culpable, se juzgó clínicamente oportuno encubrir el deseo reprimido: sólo calmado favorecería la satisfacción del deseo legítimo y la aceptación de la realidad. Junto al relajamiento instantáneo de la paciente, que por vez primera vivió la realidad, si bien a fragmentos, la libido pudo ser satisfecha en la realidad, y no en el autismo, como hasta entonces (14). Poco a poco, fue ampliándose la dieta de Renée, gracias a la autoridad materna ejercida por su analista. Respecto a las alucinaciones auditivas, ésta las aceptaba, y decía a la paciente que tales voces 
eran débiles, mientras que las suyas eran fuertes; de este modo la preservaba de los potenciales perseguidores amenazantes.

Preconcibió acaso algunas de las ideas formuladas después por D. W. Winnicott sobre los objetos y fenómenos de paso hacia otro estado, expresadas entre otros en Objetos transicionales y fenómenos transicionales (1953). Pues Séchehaye usó un mono pequeño de peluche para representar simbólicamente a Renée, que así podía recibir las satisfacciones que ella, por sí misma, no podía aceptar. El monito, por tanto, como objeto transicional, se ubicaba en un momento de paso hacia la percepción de un objeto netamente diferenciado del sujeto, quien así encauzaba su devenir vital hacia un relación de objeto propiamente dicha, que en ningún modo abolía/negaba la función del objeto transicional, convertido así para siempre en un campo neutro de experiencia (15). Más tarde, usó a Moisés y Ezequiel, dos muñecos de forma humana de desigual tamaño, a los que Renée tratará como una prolongación vital de sí misma; el primero se referirá a su vida pretérita, el segundo a su vida actual. Hubo terribles celos y fantasías sádicas de Renée -a las que después daría expresión en un tigre de peluche-, hacia los otros pacientes, inconscientemente asemejados a sus temidos hermanos menores, a quienes Séchehaye atendía en su propia casa, como Renée (que dejó la pensión donde residía). No obstante, por deseo de la familia, Renée será internada en una clínica, fracturándose así el vínculo generado con la mamá-analista, lo que, junto a complicaciones físicas, la conduce a un estado regresivo profundo, donde las conductas autolesivas y las alucinaciones auditivas vuelven a estacar (14).

En la primavera de 1936, transcurridos casi seis años desde el inicio de la terapia, comienzan a evidenciarse los progresos psicoterapéuticos originados por los tratamientos simbólicos ininterrumpidos y sistemáticos realizados. Así, al llegar el verano, se suprimen los calmantes y las correas de contención, ausente ya la tentativa de suicidio, se la deja sin control alguno durante 45 minutos. Por otro lado, al igual que con la ingesta, Renée fue capaz poco a poco de introyectar y manejar sin elevada angustia el amor materno hacia su cuerpo, confiriendo al cuidado personal una atención antes ignorada. Las progresivas adquisiciones y logros personales que la paciente realiza, merced a lo que se resuelve el complejo del destete y se asienta la formación del yo, convencen a Séchehaye para retirar símbolos antes usados, como el monito de peluche o Moisés/Ezequiel, accediendo así primero a la fase anal, para después a la genital, en la que el deseo fálico de Renée se materializa en el pulverizador con el que placenteramente rocía a su mamá-analista durante un cierto tiempo.

Paralelamente, el pensamiento mágico, como las ideas animistas que gobiernan el proceder intra/interpsíquico de Renée, se ven contrastadas, debiendo ésta enfrentarse a ellas, primero ayudada por Séchehaye, para después sola, fase del proceso etiquetada como terapia de las asociaciones mágicas. En lo que respecta 
HISTORIA DE LA PSIQUIATRÍA

a las medidas reeducativas, usadas para reestructurar la personalidad de Renée, están la actitud comprensiva, como de genuina escucha y sinceridad que alientan su praxis clínica, ingredientes similares para nosotros a los de C. R. Rogers (19021987) formulados en su peculiar visión del proceso psicoterapéutico (16). En esta labor analítica de renacer o de (re)construcción de Renée como sujeto humano, cognitiva y afectivamente, que del apego seguro a la mamá-analista transita lentamente hacia la propia individuación, figuran otras medidas como son las del establecimiento de un estricto horario para la realización de actividades, comidas y distintas tareas programadas para facilitar que la paciente recorra el camino que lleva desde sus necesidades narcisistas a las de contacto con la realidad exterior para terminar con las de carácter social.

Si nos atenemos al testimonio personal de Renée, elaborado a comienzos de 1938 a petición de Séchehaye, que lo insertó en su ensayo La realización simbólica (1947), como al estado de aquélla en abril de 1940, se curó totalmente, siendo esto confirmado por psiquiatras y psicoanalistas que la examinaron y trataron, entre los que figuran Bersot, Boven, Danjou, Flournoy, Forel, Ladame, Morel, Nunberg, Odier, Redalié, Repond, Piotrowski, de Saussure, de Yongh y Weber, a lo que Séchehaye añade el suficiente equilibrio psíquico que Renée expresaba a nivel práctico, como social, médico y psicoanalítico. Esto, sin embargo, no impedía que ante situaciones ansiógenas aquélla reactivase mecanismos psíquicos de carácter esquizoide, que Séchehaye explica argumentando que «el método simbólico ha curado los conflictos ocasionados por los complejos, pero no tiene influencia sobre las tendencias fundamentales de la constitución esquizoide», pues, como en la neurosis, en donde se eliminan los conflictos, sin que por ello la constitución que le daba su carácter haya cambiado, sucede aquí. A ello además se unía la coexistencia en Renée de otras fallas sociales y vinculares, lo que sin duda cuestiona su completa curación (14). Vinculado con esto, dos décadas después, en una misiva del 3-III-1960, remitida al Dr. Christian Müller, Séchehaye manifestaba su temor de que detalles íntimos de los historiales de Renée se hicieran públicos, desvelando así datos confidenciales tales como su auténtica identidad, diagnósticos formulados o éxito-fracaso terapéutico de la realización simbólica, según se fuera partidario o detractor de tal técnica, por lo que le exhortaba a que velara por el secreto profesional, para lo que adjuntaba dos autorizaciones, una de ella y otra de su ex-paciente, en las que fijaba a Müller garante y único con acceso a los historiales (17). Con todo, Séchehaye matiza que, para que la realización simbólica sea eficaz como terapéutica, los progresos deben tener lugar en las sesiones, y no fuera, pues en tal caso sólo incidirán a nivel intelectual y no afectivo, al mezclarse con la realidad y no ser estrictamente simbólicos. La realización, además, debía ajustarse a la fase psicosexual en la que Renée se hallara, lo que exigía el lento tránsito por todas ellas. Asimismo, el símbolo tenía que ser aplicado directamente 
por un sujeto, pues, de la misma forma que todo conflicto psíquico y falla afectiva se genera en la interacción fallida con otro, la restauración del sí mismo precisa un vínculo capaz de restañar heridas narcisistas, nutrir afectivamente y reorganizar el universo íntimo del sujeto sufriente.

\section{Diario de una esquizofrénica: la experiencia terapéutica vivenciada como paciente}

Según Séchehaye (18), con este trabajo pretendía mostrar el lado interior de la terapia, cuando ella, como psicoterapeuta, se juzgaba ubicada en su homólogo exterior, siendo así consciente de que ambos lugares del encuentro humano tecnificado -que conforma todo proceso psicoterapéutico (19)- son cruciales para describir y explicar la dinámica interna creada y desarrollada en éste. Corporeizando tales premisas, una vez terminada la terapia, Renée le refería a Séchehaye los primeros sentimientos de irrealidad que recordó vivenciar, que retrospectivamente situaba a los cinco años y que en desigual fortuna se extendieron hasta cumplir los doce, cuando aumentaron en intensidad y frecuencia. Todo dificultó su tránsito normal de la escuela primaria, en la que fue premiada, a la secundaria, dado su alejamiento progresivo de la realidad, que la sumía en una lucha contra sus alucinaciones y trastornos perceptivos. Con todo, había momentos en que reconectaba con la realidad, dotando de vida a árboles, viento, etc.; en su retorno a su universo imaginario había un animismo que ya no abandonará, y que, junto al pensamiento mágico y otras alteraciones de todo tipo (extrañeza, despersonalización, etc.) marcarán su enfermedad mental. Renée, sin embargo, confiesa que no se sentía enferma, al no representar la locura para ella una enfermedad sino una suerte de viaje psíquico a un país desconocido, al que designa país de la iluminación, en donde el rasgo distintivo era estar permanentemente en la irrealidad más absoluta.

Allí establecida, para no ser internada legalmente en contra de su voluntad, pues Séchehaye contacta con el director del consejo de vigilancia de alienados y médico de cabecera de Renée, ésta ingresa en el pabellón de excitados de una clínica privada para enfermos nerviosos, fuera de Ginebra, donde permanece un tiempo. Está asediada por objetos perturbadores y un asfixiante sentimiento de fusión vivenciado hacia las cosas que conforman el Sistema de castigo autocreado/autorreferencial, merced al cual da sentido a la irrealidad en la que se debate y gravita su devenir existencial (18). Tal sistema punitivo, al que se resiste pero acatado, la sume en un gran agotamiento psicofísico al que se une la estrecha vigilancia a la que la someten quienes la cuidan y custodian, dado el temor que hay de que se prenda fuego a sí misma y a las instalaciones, para así obedecer al mencionado sistema. En su desesperada lucha interior, el amor que le profesa su mamá-analista favore- 
HISTORIA DE LA PSIQUIATRÍA

ce su alta terapéutica, siendo acogida por Séchehaye en su propia casa por espacio de tres semanas, para luego ser admitida en una clínica privada ginebrina, regresando después a su hogar familiar, donde cae presa de una total indiferencia. Tal vez por ello, de nuevo Séchehaye, junto a las sesiones clínicas, pasa con Renée tres semanas en una localidad costera, lo que decepciona a ésta, que ya no percibe a aquélla como la mamá-analista, pese a los esfuerzos internos que realiza, sino sólo como la señora Séchehaye, lo que la sume en una gran agitación interior, retornando tal rol dual cuando da comienzo la sesión analítica diaria.

De vuelta a Ginebra, nuestra enferma transita por varias clínicas privadas, en las que vivencia momentos de enorme agitación y de crisis internas de culpabilidad, para después recaer en una absoluta indiferencia. El mundo, señala, es como una película proyectada donde ella no participa y frente a la que siente una profunda e inmotivada hostilidad. Asimismo, las manzanas sobre el pecho de Séchehaye se tornan para ella en símbolo desplazado de la leche materna, regresión oral que propició un estrecho contacto con aquélla, a la que convirtió en mamá-alimento. Poco a poco, fue adquiriendo autonomía personal respecto a su mamá-analista, de la que fue desapegándose primeramente en lo alimenticio, para después en la limpieza y cuidado personal, consiguiendo luego pensar en aquélla sin que se alterase su visión de la realidad. Con todo, Renée reconoce la fragilidad que le une a la realidad, conexión/desconexión en la que resulta crucial Séchehaye, favorecedora o aniquiladora para aquélla de tal nexo real. Dos años después, la individuación de Renée se evidencia también en la percepción de la realidad, que es capaz de encarar pese al descontento hacia sí de Séchehaye (18). A modo de conclusión, Séchehaye afirma que la esquizofrenia conforma una enfermedad del yo, específicamente de desintegración de éste, en cuyo origen, tal como corroboró en La realización simbólica, los impulsos primarios, especialmente de tinte oral y agresivo, desempeñan un papel fundamental, resaltando a su vez la importancia crucial que poseen las frustraciones iniciales en la desintegración del yo. Por ello conduce su labor clínica a la regresión psíquica de Renée al estadio fetal, para así restaurar mediante la satisfacción alucinatoria su necesidad de ser nutrida biológica y afectivamente por la mamá-analista, lo que propicia el advenimiento de un proceso de deconstrucción yoica, donde la pretérita relación fusional-autística con la figura materna se trastoca en individuación no traumática.

\section{Otros escritos que esclarecen la clínica de Séchehaye}

En 1942, aglutinados bajo el título de Reeducación psíquica, doctrinas y métodos, vieron la luz en el diario l'Essor, tres artículos de M. A. Séchehaye, fechados el 17 de abril, 1 de mayo y 26 de junio (20). Estaban escritos en un esti- 
lo sencillo y divulgativo, sin por ello perder rigor, para que así los lectores cultos y legos en modelos de intervención clínica supieran del desarrollo histórico y estado actual de la psicoterapia; no quería vulgarizar el saber psicoanalítico, sino visibilizarlo y hacerlo más accesible al público en general. En el primero, aborda la necesidad en muchos sujetos de una «reeducación psíquica», esto es, una suerte de reorganización cognoscitiva y emocional de la que se derivará cambios en el funcionamiento psíquico y la conducta; señala como herramientas clínicas para lograrlo terapéuticas como la persuasión filosófica, religiosa, racional, sugestión, autosugestión, etc. En el segundo, añade el gran descubrimiento del psicoanálisis por Freud, tras el magisterio recibido de J. Breuer (1842-1925), así como las primeras deserciones acontecidas en el seno de la comunidad psicoanalítica (Jung, Adler, Stekel, Rank, etc.), de las que se derivaron el auge o descrédito de desarrollos teórico-técnicos psicoanalíticos ulteriores. Critica a quienes han reducido la matriz psicoanalítica freudiana a una teoría pansexualista, pues parece circunscribir ésta solamente a las neurosis actuales. En el tercero, aboga por la útil aplicabilidad de la reeducación psíquica, no ya psicoterapéutica, sino de naturaleza psicopedagógica, al terreno de los niños retrasados, difíciles, etc., para lo que juzga vital elaborar un plan individual de aprendizaje; sigue a Claparède, quien, sirviéndose de las capacidades e intereses personales de cada alumno, alentaba su curiosidad intelectual: son ideas que aún inspiran todo proceso de enseñanza-aprendizaje. En cuanto a los niños difíciles, asimilables hoy a los «menores infractores», defiende la necesidad de crear tribunales especiales de justicia, cuyo objetivo sea su reeducación, mostrándose contraria a imponer medidas punitivas, mezcla de escarmiento y venganza social. De forma semejante, casi dos décadas atrás, A. Aichhorn (1878-1949), cuya trayectoria conocía Séchehaye, convenía en que, más que un juez de lo penal, hubiera uno encargado de la custodia de los jóvenes delincuentes, subrayando que lo más idóneo es que estuviera formado en el trato a menores y desarrollara su labor en colaboración con otros profesionales (médicos, psicoanalistas, etc.), con un genuino compromiso de reinserción social (21). Para los niños neuróticos, en cambio, Séchehaye juzgaba oportuno usar el análisis infantil, en donde destaca las aportaciones realizadas por mujeres; señala a A. Freud (1895-1982), pero no a M. Klein (1882-1960), lo que supondría un alinearse con ideas no kleinianas. Como colofón señala, en sintonía con ideas jungianas, que habría que erradicar el mal que aquejan estos niños en su origen, que sitúa en la familia y más en los padres, responsables de su ulterior condición psíquica (20).

$\mathrm{Al}$ año siguiente, y fruto de una conferencia, se editaba El psicoanálisis al servicio de los desalentados (1943). Séchehaye comenzaba señalando por qué algunos sujetos, sin afección física subyacente, habían perdido el impulso interior a amar, trabajar y sentirse vivos (22). Consideraba que tales individuos estarían aquejados de una psiconeurosis, la cual les haría ser portadores de un profundo 
HISTORIA DE LA PSIQUIATRÍA

sentimiento de inferioridad, como de una inhibición neurótica de su pensamiento y acción, que en otros sujetos también se evidenciaría en fobias, rituales, compulsiones y una ansiedad difusa y paralizante que se aleja y retorna ignorando el sujeto que late bajo ésta. En tal sentido, afirma que, aun siendo bienintencionado, decirle a un sujeto que no piense en tales síntomas, cuando éstos le asedian, resulta ineficaz para librarse de ellos y sentirse satisfecho consigo mismo y los demás. Propone, pues, que el neurótico se someta a la terapia freudiana, a la que no juzga como la panacea, aunque valora sus éxitos y fracasos, los primeros de los cuales juzga que dependen principalmente de la seria formación del analista y de su intuición y prudencia, mientras que del paciente considera que debe poseer una gran inteligencia y paciencia particular, dada la larga duración y coste del tratamiento. En una suerte de didactismo pedagógico, explica tras ello cómo opera el psiquismo, esto es, cómo la conducta interna y externa reposa en determinantes conscientes e inconscientes, los últimos de los cuales, a lo largo de la terapia realizada, se tornan accesibles en desigual grado a la conciencia del sujeto. Y hace también alusión a las pulsiones de vida y de muerte que gobiernan nuestros pensamientos y acciones, tendencias primitivas que Dios habría creado y que, con los cuidados oportunos, pueden llegar a tornarse en elementos de civilización y espiritualidad (ello refleja su formación protestante). En lo preventivo, en cuanto al origen y desarrollo de la neurosis infantil, afirma que hay que estar muy atentos para no reprimir bruscamente los sentimientos del niño; lo ejemplifica en el complejo de Edipo, o en el nacimiento de un segundo hermano, y señala la conveniencia de que en ambos casos los padres actúen con dulzura, preparando al niño para los cambios que se darán en su dinámica personal y familiar, convencida de que ello facilitará su tránsito psíquico y emocional necesario.

Las siguientes cuestiones abordadas por Séchehaye hacen referencia a las dificultades técnicas inherentes a todo proceso analítico, señalando en primer lugar las inhibiciones internas de los pacientes para asociar libremente o establecer una buena alianza terapéutica, en lo que refiere crucial los fenómenos transferenciales y constransferenciales movilizados. En segundo término, destaca la importancia de los sueños, que siempre juzga como una realización de un deseo o expresión de un temor del que deseamos escapar, aludiendo como otras manifestaciones del inconsciente a los actos fallidos. Devuelta la salud psíquica al enfermo, termina para ella la labor del analista: «Es al conductor espiritual al que le incumbe, ahora, la misión de conducir su alma hacia una vida moral y conducirlo hacia una evolución serena, como a amar a su Padre celeste con toda su alma y al prójimo como a sí mismo» (22).

Seis años después, aparecerá Diagnósticos psicológicos, en cuya introducción Séchehaye habla de las dificultades inherentes a la labor diagnóstica, para la que recomienda prudencia y responsabilidad, especialmente para quienes 
la inician. Lo ilustra con una amplia casuística, en posibles situaciones clínicas y en las acciones psicoterapéuticas emprendidas por ella, que justifica después de un riguroso debate con una psicóloga novel, interlocutora ficticia que objeta lo dicho, sin que lo llevado a cabo reconozca que implique la única solución factible para cada caso clínico tratado (23). En el primero de ellos, «¿Parálisis histérica en un niño de cuatro años?», señala cómo a requerimiento de dos médicos que dudaban sobre el diagnóstico de neurosis de conversión emitido para una niña pequeña fueron solicitados sus servicios como psicóloga, evidenciándose tras su acción psicoterapéutica que las parálisis observadas en brazos y piernas no eran de carácter funcional, esto es, fruto de conflictivas psíquicas, aun cuando inicialmente para los galenos resultara difícil explicar satisfactoriamente la sintomatología por anomalías neurológicas, y no por factores psicógenos como la fijación edípica a la figura paterna, o los celos ante el nacimiento de un nuevo hermanito, etc. Por ello, sin negar la posible influencia de lo ambiental sobre lo orgánico, se modificó el diagnóstico: parálisis infantil complicada por una ligera encefalitis. Con ello, Séchehaye afirma que se preservó a la niña de sufrir una parálisis orgánica de mayor gravedad, reduciéndose las secuelas físicas y psíquicas a una escoliosis y ligera atonía muscular, cierta lentitud intelectual y una disminución de la vivaz imaginación.

La problemática del segundo caso alude a las dificultades que en ocasiones surgen para conciliar deseos personales con ambiciones familiares, concretamente cuando el joven debe decidir hacia dónde encauzar su futuro profesional, siendo entonces cuando el consejero vocacional le ayudará a conseguir una solución que intente satisfacer a todos, sirviéndose en esto de sus conocimientos y experiencia, además de cuestionarios, entrevistas y observaciones. A la búsqueda de la mayor autonomía y dignidad a una anciana retrasada mentalmente dedica el tercer caso, señalando algunos de los conflictos y adaptaciones que el propio sujeto y sus familiares o entorno inmediato han de enfrentarse cada día, y que, entonces como hoy, afectan al amplio espectro de personas que poseen algún tipo de discapacidad. En el cuarto caso la discapacidad sigue presente, desde que se presenta a un niño de nueve años que no sabe leer y a quien tras un exhaustivo análisis de sus competencias y destrezas intelectuales se le juzga afecto de una alexia de evolución y discretos trastornos del lenguaje, recomendando Séchehaye que, dado el egocentrismo que también manifiesta, se interaccione con él desde una actitud comprensiva, favorecedora de un intercambio de experiencias sociales y emotivas.

El cambio de actividad laboral en la adultez es la siguiente temática que analiza en una mujer que paralelamente está bajo tratamiento analítico, y para quien tal viraje profesional parecía más responder a la realización de deseos inconscientes que a la satisfacción de necesidades personales objetivas de orden 
HISTORIA DE LA PSIQUIATRÍA

superior. Ilustrando esto refiere como ejemplo el de una enfermera que inconscientemente hubiera elegido tal labor clínica-asistencial para ejercer su dominio sobre el otro y no para aliviar sufrimiento alguno. Por eso Séchehaye recomienda a esta joven terminar primero la terapia analítica iniciada, para después, si así lo precisa, contactar otra vez con ella en busca de reorientación profesional. La viñeta clínica de la que Séchehaye se sirve en el sexto caso es la de un adolescente que sometido a tratamiento psicoanalítico por el director-médico de una clínica de enfermedades nerviosas es derivado a ella para que también lo examine y establezca un programa de estudios ajustados a sus particulares singularidades. Para ello, antes de tomar cualquier decisión currículo-formativa, analiza la historia de vida del chico, en la que constata la existencia de crisis nerviosas epileptiformes, como de traumatismos craneales que le han ocasionado parálisis en el hemicuerpo lateral izquierdo y el pecho, haciendo su voz apenas audible y el habla entrecortada. A ello también se añade haber sido víctima de lo que hoy conocemos como TEPT (trastorno de estrés postraumático), estado patológico del que compañeros de internado se aprovecharon para infligirle malos tratos y escarnio institucional. Partiendo de la incoercible necesidad de este joven para expresar sus más profundas emociones, como testigo y víctima de la guerra y los bombardeos, Séchehaye le anima a ser escritor, en un ejercicio de expresión emocional catártico, teniendo siempre para ello presente las limitaciones y mermas psicológicas y físicas que este chico mantendrá a lo largo de su devenir vital por las complicaciones neurológicas acaecidas en su infancia.

De vuelta al terreno de las enfermedades mentales, se ocupa en el siguiente caso de la esquizofrenia infantil, donde parte del tratamiento psicoterapéutico llevado a cabo a una niña de 8 años, a la que inicialmente se juzgó afecta de neurosis, para lo que se había realizado un profundo estudio de su personalidad. Sin embargo, dado el agravamiento de la conducta y carácter de la niña (actitud rígida, falta de contacto con la realidad, rasgos autistas), cuando ya hacía un tiempo razonable que se habían puesto en marcha medidas como el consejo psicológico a los padres y la adaptación curricular en la escuela privada, le hicieron pensar a Séchehaye que tal sintomatología correspondía más a un cuadro de naturaleza psicótica que neurótica (23). Con ello presente, y ante lo fallido de intervenciones previas, decide servirse del saber psicoanalítico, para lo que además de analizar a la niña, usando el juego, el dibujo y ciertas pruebas diagnósticas infantiles, logra acceder intuitivamente a través de la escritura al universo íntimo de aquélla, formulando explicaciones dinámicas acerca de lo que a nivel conflictual acontece en el psiquismo de su jovencísima paciente. De igual forma, en la narrativa analizada, se detecta con facilidad la gran ternura y afecto en el trato con la niña, a pesar de lo que sus progresos intelectuales, conductuales y afectivos resultan efímeros, dada la completa desatención de sus progenitores, 
quienes juzgaban curada a su hija e innecesario así seguimiento o recomendación alguna, de ahí que sólo seis años después volvieran a solicitar el consejo escolar para aquélla, advirtiendo entonces Séchehaye que los rasgos y patrones esquizoides se habían acrecentando, aunque sin ocasionar desajustes personales y familiares de antaño, persistiendo eso sí ciertos síntomas (v. g., enuresis diurna y nocturna). A los 18 años, ante el avance inexorable de la enfermedad esquizofrénica, se decide internarla, siendo sometida a terapia electroconvulsiva, lo que se muestra a todas luces ineficaz, retornando entonces a su hogar y de allí a Italia, donde no mejora su condición psíquica.

En otro caso incita a no dar nada por sentado: «Responsabilidad del psicoanalista en el establecimiento del diagnóstico», detalla cómo un señor que solicita análisis argumentando desavenencias maritales y con su vástago, tiene una pérdida muy fuerte de peso sin base objetiva así como complicaciones estomacales e intestinales. Desoye el consejo de realizar un completo examen físico, con el que podría descartarse la base orgánica de sus dolencias somáticas, al estar convencido de la naturaleza psicógena de lo que le sucede. Por ello inicia una terapia en la que el psicoanalista dio por sobreentendido que no aquejaba trastorno somático alguno. La radioscopia practicada evidenció, sin embargo, que padecía un cáncer intestinal en fase muy avanzada, ya inoperable; halló al menos consuelo en su esposa e hijo.

El consejo escolar, aunque bajo dos ópticas distintas, como son el bajo rendimiento escolar de un alumno por un lado y la orientación profesional de un estudiante por otro es objeto de los dos casos siguientes. Del primero destacan como rasgos notables que, ante la suposición de inhibición intelectual por razones neuróticas, un examen psicológico riguroso muestra que el diagnóstico más adecuado es el de neurosis de abandono con un fondo constitucional esquizoide, al mantenerse después de un proceso psicoterapéutico síntomas como dificultad para contactar con otros, tendencia marcada hacia las racionalizaciones, al igual que una fuerte represión de la afectividad, todo lo que se refleja en una fría y distante actitud ante situaciones estresantes generadoras de respuestas emocionales. Lo que se ha eliminado o reducido, por el contrario, juzgándose así cierto logro psicoterapéutico, son otras respuestas neuróticas como miedo, obsesiones, inhibición permanente o perseveración del pensamiento, al ser su expresión desajustada y contraria a una más adecuada adaptación del sujeto a los entornos donde se desenvuelve. Del segundo, es interesante referir cuáles son los factores que el orientador debe tener en cuenta para ayudar a un joven a elegir sus estudios o en qué actividad profesional formarse; afirma que la función orientadora no debe constreñirse a los resultados obtenidos en las distintas pruebas psicológicas usadas, debe también sustentarse en los intereses profundos del estudiante, en su situación personal y sociofamiliar; y muestra bien lo difícil que resulta conciliar las aspiraciones personales y familiares. 
HISTORIA DE LA PSIQUIATRÍA

En el penúltimo caso, «Psicoterapia a un enfermo físico gravemente afectado», relata cómo ayudó a un paciente a comprender y aceptar en mejor grado la singular interacción somática-psíquica que existía en los males que en ambos teatros, el del cuerpo y el de la mente, aquejaba, y por el que el diagnóstico final había sido el de neurosis de angustia con un fondo constitucional neuropático. Buscando alivio a la intensa angustia del sujeto, se sirve del llamado análisis psicológico, por el que entiende dar explicaciones al paciente acerca de su forma de pensar y de encarar los conflictos, sin necesariamente acceder a las causas profundas. Deja así la terapia psicoanalítica para otra casuística: una visión clínica que la situaría en las cercanías de ciertas terapias racionales o de cambio cognitivo actuales, donde el cuestionamiento de ideas irracionales o la reestructuración cognoscitiva conforman parte del trabajo y objetivos psicoterapéuticos. Termina el libro con el caso de una mujer afecta de una encefalopatía infantil congénita intrauterina, que le ha lesionado el cuerpo estriado y dejado así secuelas graves, particularmente una hipertrofia de los miembros superiores y del cuello, como espasmos múltiples, movimientos coreoatetósicos y una disartria que torna el lenguaje oral casi ininteligible salvo para los que ya estén habituados a él. Y, aun cuando hay un desarrollo mental disarmónico, las funciones intelectuales están relativamente bien conservadas, sobre todo las de comprensión rápida. Ante esto, Séchehaye señala que su labor clínica y de orientación profesional se ceñía a las dificultades psíquicas inherentes a tal cuadro neurológico y no a otras; alentó a su paciente para que se formara en grafología, lo hizo, y pudo superar su sentimiento de inferioridad y obtener cierta felicidad.

En Una nueva psicoterapia para la esquizofrenia, subtitulado Alivio de las frustraciones por la realización simbólica (1956) (6), Séchehaye arranca con las dificultades que hay para establecer sus causas primarias, al existir tratamientos biológicos como la insulina o la terapia electroconvulsiva que no han mostrado la eficacia esperada. Confiere así a la psicogénesis un mayor protagonismo, de lo cual sería reflejo la importación de términos y premisas provenientes de la filosofía existencialista, a diferencia de lo sucedido con la paranoia o la melancolía; ello ha permitido obtener un mapa más completo de la esquizofrenia, y por ende de las medidas psicoterapéuticas y psiquiátricas más adecuadas para su abordaje-tratamiento y potencial curación. Y aun cuando sean valiosas las ideas del saber psicoanalítico para la comprensión de tal anomalía, reconoce lo ineficaz que resulta la terapia freudiana convencional para tratarla, así que apuesta por la realización simbólica, técnica psicoterapéutica cuyos resultados positivos evidencia la reversióncuración operada en la dinámica psíquica-conductual de Renée, paciente a cuyo caso clínico dedica el primer capítulo. A continuación, trata las exigencias clínicas requeridas en el contacto con el esquizofrénico y su universo interior, al juzgarlo como la pieza clave del ulterior éxito o fracaso terapéutico, ayudándose en 
sus especulaciones del existencialismo y de su propia y rica in-trospección, guiada por la firme convicción de que el esquizofrénico siente y es receptivo, en mayor o menor grado, a la presencia del otro, lo que para nosotros es condición necesaria, pero no suficiente, al precisarse también la voluntariedad y necesidad interna de aquél para interactuar con otros e ir así más allá de la mera percepción sensible de éstos.

En pos de tal logro, juzga como tarea previa que se desvelen qué mecanismos defensivos patológicos erigió el esquizofrénico para protegerse de la realidad interna-externa que sentía amenazante. Pero, aun cuando lograra establecer vínculos afectivos con otros, la perdurabilidad de éstos no está garantizada, al oscilar su patrón cognitivo-conductual entre la búsqueda de cierta proximidad y de lejanía, dada la ambivalencia que guía sus tentativas exploratorias, pues siempre se repliega a un lugar seguro. Asimismo, advierte del posible error de malinterpretar ciertas conductas del sujeto esquizofrénico como expresión de la incipiente creación de un genuino vínculo emocional con otro, al ser en realidad maniobras de aquél para rellenar el profundo abismo que lo separa de los demás, en un intento de resolver el dilema que le enfrenta al ansiado y temido deseo de comunicarse. Aquí subyacen los profundos temores del esquizofrénico de que al contactar con otros se reavive su emotividad, colapsando así el equilibrio psicótico alcanzado, que, a diferencia del proceder psíquico neurótico, Séchehaye, en el esquizofrénico, equipara, sirviéndose de ideas piagetianas, al desplegado por el niño en la fase de realismo moral, señalando a su vez la renuente negativa que a causa del estado de gran agitación interior aquél podría manifestar y que, aislada o conjuntamente, comprometería en desigual forma y grado su anhelado intercambio con el medio.

Por ello, y así lo evidencia el tercer capítulo, deben conocerse también las necesidades primarias, dentro de las que figuran la expresión simbólica de necesidades fundamentales y de los distintos «universos creados» en cada sujeto esquizofrénico, y las reacciones, que clasifica en positivas o compensatorias y negativas, a las frustraciones internas-externas que subyacen a tal enfermo, cuyo origen y ulterior destino psíquico remonta al modo en el que fueron conformados los tempranos vínculos afectivos madre-bebé, que como a la fase oral juzga debe dedicarse más investigación, para así estar en mejores condiciones de saber qué impide o gratifica al esquizofrénico para no salir del universo psíquico por él creado, en contraposición al que se le oferta una realidad más tolerable. Las pautas y los criterios para entrevistar a parientes desde el método de la realización simbólica es objeto del siguiente capítulo, donde recalca el nexo inextricable que existe entre la afectividad exhibida por el esquizofrénico y la desplegada por sus allegados, la cual oscila desde la objetividad clínica, negadora de la condición psíquica esquizofrénica y aparentemente ajena a ellos, a la de los que indagan en su historia vital, en busca de alguna explicación satisfactoria para tal desgracia personal-familiar, 
HISTORIA DE LA PSIQUIATRÍA

de la que algunos responsabilizan a su cónyuge o antecedentes familiares hereditarios, en un intento de evadir toda responsabilidad en lo sucedido y encontrar así alguna causa física que explique tal enfermedad (6). Por ello las preguntas a parientes durante la entrevista deben encauzarse en obtener información relevante que ayude al profesional en el tratamiento psicoterapéutico del esquizofrénico, y nunca a generar angustia, culpa, etc., sobre aquellos, pues en último término tal cosa revertirá en el intercambio afectivo y condición psíquica de uno y otros.

En el quinto capítulo aborda los distintos tipos de observación que a tal enfermo mental puede realizarse en términos de la realización simbólica, señalando como métodos el psiquiátrico, psicoanalítico y existencial, que si bien considera útiles, al explorar cada uno una parcela del psiquismo esquizofrénico, resultan insuficientes para diseñar una terapia capaz de curar o compensar satisfactoriamente tal condición psíquica, por lo que propone un método de observación funcional y dinámico, del que puedan extraerse explicaciones funcionales y profundas de los diversos actos conductuales del sujeto. En tal sentido, conocer la fase (oral, anal, etc.) en que el esquizofrénico se halla será útil para desentrañar las necesidades-deseos que movilizaron su regresión psíquica, aportando mayor credibilidad a las explicaciones. En el sexto, analiza los procesos del pensar esquizofrénico, cuyo contenido y forma juzga de igual interés, señalando necesario para la génesis de un pensamiento infra-lógico, el adualismo, esto es, la confusión entre el yo y el no-yo, el realismo intelectual, afectivo, moral y automático, expresión cada uno de la primacía del modelo interno sobre la realidad externa, mientras que como mecanismos y procesos incluye la asimilación, proyección, desplazamiento, condensación y participación. Finalmente, en el séptimo, se ocupa de la realización simbólica de las necesidades internas del sujeto esquizofrénico, el cual se debate entre su ansiada realización y la prohibición o castigo fantaseado que cree le sobrevendrá de ser aquéllas materializadas, instante en que terapéuticamente deberá trabajarse en la erradicación o atenuación de su culpa.

En 1960 se edita Técnicas de gratificación en psicoterapia analítica: indicaciones y contraindicaciones (24). Séchehaye, apoyándose en la literatura psicoanalítica, afirma que sea cual sea la terapia analítica usada, ésta gira entre dos polos opuestos, el de la frustración y el de la gratificación, y se interroga acerca de cuándo el analista precisa adoptar una actitud más gratificante, de suerte que trabaje con su paciente en un plano dialéctico o en su homólogo regresivo de lo infraverbal y en qué fase del desarrollo del análisis está indicado introducir modificaciones técnicas, atenuando así el rigor de la neutralidad terapéutica. Juzga más apropiada, como actitud interna de quienes trabajan con psicóticos, la de la gratificación, que sustenta en la interpretación y el análisis de las defensas/motivaciones del sujeto, si bien no señala pautas o reglas técnicas cerradas para su materialización mostrando sus dudas acerca de cómo cumplir las necesidades frustradas 
del enfermo, labor que dice cabe hacerse de un modo directo y concreto o de una forma mágica simbólica, fantasmática y delirante, afirmando a su vez la dificultad para establecer límites a las exigencias del paciente. Asimismo, señala la especial sensibilidad de algunos sujetos a la menor variación técnica, como sucede en los gobernados por una estructura pregenital, quienes interpretan la actitud del analista sólo como gratificante-frustrante. Señala que es la introducción dosificada de tal gratificación-frustración, que conecta con la «presencia» cercana o lejana del analista así como con la tolerancia subjetiva asumible por el paciente, lo que va permitir configurar la óptima distancia psíquica que aquél es capaz de soportar hacia la figura de su analista.

A la vez también manifiesta que para los sujetos con un yo débil (que no cabe sin más juzgar de prepsicótico), las diversas técnicas de gratificación conforman habitualmente sólo una fase más del análisis en curso, constituyendo una forma de gratificar al sujeto la de revelarle al analista como una personalidad real, según expresión del analista de origen rumano S. Nacht (1901-1977), de algunas de cuyas ideas Séchehaye se sirve. Recomienda que en los su-jetos con defensas estructuradas no resulta conveniente adoptar la técnica de gratificación, al menos al inicio del análisis, desde que colmar esas necesidades instintivas la vivencian como algo prohibido, lo que obliga a mantener una gran reserva y trabajar terapéuticamente fortaleciendo al yo. De igual forma, debe conocerse en qué fase-de irrupción (en que el sujeto se halla presa de una angustia masiva, donde la frontera yo-no yo es inexistente) o de cronicidad de la psicosis- se halla el sujeto, pues de ello dependerá la naturaleza y forma concreta de gratificación. En la fase de irrupción consistirá en dar al esquizofrénico una referencia, un punto real y fijo al que asirse (24). En la fase crónica, constituidas las defensas psicóticas, la forma en que el sujeto podrá ser gratificado, dado el temor interno que posee de ser asfixiado, absorbido, por el otro, residirá en que el terapeuta esté disponible y no traspase la distancia crítica que aquél exige.

Debe entonces primar las necesidades del yo sobre sus homólogas pulsionales, las cuales luego serán satisfechas, sucediendo así que el miedo a ser absorbido será reemplazado por el deseo interno de ser absorbido y el deleite pasivo de sentirse tratado por otro como un sujeto en estado fetal. A diferencia de la fase de irrupción, toda tentativa del terapeuta para irse alejando de su paciente será interpretada por éste, entonces, como un abandono, como una voluntad negativa del/la terapeuta-madre de romper la fusión entre ambos creada. Habrá, por tanto, que ser prudentes, para no provocar las iras del esquizofrénico, que, una vez colmada su necesidad oral primaria, vivirá tal relación diádica como una agresividad verbal, permitiéndole entonces que exprese libremente sus fantasmas de canibalismo o actividad en el seno materno, preludio de los procesos de integración e incorporación posteriores. Asimismo, señala la diferencia que existe entre la técnica de 
HISTORIA DE LA PSIQUIATRÍA

«maternaje», por la que el esquizofrénico obtiene pequeñas gratificaciones (a la que considera insuficiente por sí sola para una modificación estructural de la psicosis, aun cuando produce una mejora sintomática transitoria y sedativa de la angustia), y la técnica de la realización simbólica, que cuenta con las resistencias del yo psicótico, y respeta la porción adulta del esquizofrénico, por lo que gratifica la parte regresiva, y resulta así más indicada que la anterior. La distancia, afirma también, entre el esquizofrénico y su terapeuta, no debe conducir al equívoco de una presunta autonomía del sujeto, y por tanto de la posibilidad de cura y terminación del tratamiento, al poder representar también el deseo de abandonar la terapia, ya por proyecciones agresivas de orden transferencial, ya por la angustia de ser devorado, ya por el miedo de sentir su libertad alineada por el otro (24). Si, por el contrario, tal independencia es genuina, será el momento de colectivizar la terapia del esquizofrénico, término con el que Séchehaye designa la intervención de otros en la recién iniciada autonomización de aquél, logro deseado o temido, con el que alcanzará el objeto esencial de la cura, la re-síntesis o rearticulación de su universo interior.

En Psicoterapia de la psicosis (1961), Séchehaye colabora con la introducción, donde insiste tanto en el papel crucial que las tempranas fallas afectivas y frustraciones ejercen en la formación de la psicosis (25), como en su reversión, que alguien adopte el rol de objeto bueno, al provocar esto una transformación dinámica de la personalidad psicótica desintegrada. También contribuye con el capítulo «La función curativa de los símbolos en un caso de neurosis traumática con reacciones psicóticas» (26), que se centra en el caso clínico de una mujer que pierde la custodia de su hija, y para quien la biblioteca pública a la que acude re-gularmente se conecta con vivencias penosas y sujetos de su vida pretérita y presente. De ahí el diagnóstico dado en el título, opuesto al de psicosis maniaco-depresiva o histeria conferido por otros, que Séchehaye descarta con la evidencia clínica hallada.

\section{Conclusiones}

La trayectoria vital y profesional de Madame Séchehaye no queda circunscrita al campo de los trastornos mentales, y particularmente de la esquizofrenia, en donde destaca su método de la realización simbólica, que soñaba se hubiera convertido en una eficaz terapia (6), sino a un amplio número de cuestiones, como el consejo y diagnóstico psicológico, la discapacidad y el compromiso ético con el paciente. De igual forma cabe recalcar la buena disposición y apertura de miras que poseía para trabajar en estrecha colaboración con otros profesionales, haciendo uso de la terapia freudiana en modos naturales de cura (23), entre los que cita el trabajo, el cambio de entorno o de reglas y pautas de vida. En esta línea, exprime todos los recursos técnicos y personales a su alcance, ocupando en éstos un 
lugar destacado la intuición y el sentido común, así como la creatividad, para así incrementar la efectividad psicoterapéutica. Sus raíces y su educación protestante impregnan su praxis clínica, aunque alejado todo ello de adoctrinamiento religioso alguno; sería sólo como una vía que, sustentada en valores humanos y transcendentes, puede ayudar a otros.

\section{BIBLIOGRAFÍA}

(1) Roudinesco, E. y Plon, M., Diccionario de psicoanálisis, Buenos Aires, Paidós, 1998.

(2) CIFALI, M. (s. f.), «Psychoanalysis: Marguerite Séchehaye». Recuperado el 24-I-2008 de la http://www.answers.com.

(3) Cifali, M., Comunicación personal, 5-III-2008.

(4) Fages, J. B., Historia del psicoanálisis después de Freud, Barcelona, Martínez Roca, 1979.

(5) Moser, A., «Switzerland», en P. Kutter (ed.), Psychoanalysis International. A Guide to Psychoanalysis Throughout the World. Vol. 1. Europe, Stuttgart-Bad Cannstatt, FrommannHolzboog, 1992, pp. 278-313.

(6) SÉCheHAYE, M. A., A New Psychotherapy in Schizophrenia. Relief of Frustrations by Symbolic Realization, Nueva York y Londres, Grune \& Stratton, 1956.

(7) SÉCHeHAYE, M. A. (1957), «Théorie psychanalytique de la schizophrénie», Conferencia en el II Congrès International de Psychiatrie, Zúrich.

(8) Weber, K., Comunicación personal, 16-VI-2008.

(9) FEDERn, E., Comunicación personal, 3-II- 2000.

(10) Federn, E., Witnessing Psicoanalysis. From Viena back to Viena via Buchenwald and the USA, Londres, Karnac, 1990.

(11) OdIER, CH., «Prefacio», en M. A. SÉCHEHAYE, La realización simbólica y Diario de una esquizofrénica, México, FCE, 1988, pp. 9-13.

(12) Saussure, R. de (1964), Journal de Genéve, n. ${ }^{\circ} 159,9$ de julio, p. 13.

(13) MeILI-Dworetzki, G., «Prólogo», en M. A. SÉCheHAye, La realización simbólica y Diario de una esquizofrénica, México, FCE, 1988, pp. 7-8.

(14) SÉCHeHAYE, M. A., La realización simbólica y Diario de una esquizofrénica. Parte I. La realización simbólica, México, FCE, 1988, pp. 15-114.

(15) Laplanche, J.; Pontalis, J.-B., Diccionario de Psicoanálisis, Barcelona, Labor, 1987.

(16) SÁnchez-Barranco, A., Historia de la psicología, Madrid, Pirámide, 1996.

(17) MÜlLER, CH., Comunicación personal, 27-IV-2008.

(18) SÉCHEHAYE, M. A., La realización simbólica y Diario de una esquizofrénica. Parte II. Diario (Autoobservación de una esquizofrénica durante el tratamiento psicoterapéutico), México, FCE, 1988, pp. 115-209.

(19) SÁnCheZ-Barranco, A., Comunicación personal, 5-III-1999.

(20) SÉCHEHAYE, M. A., «Rééducation psychique, doctrines et méthodes», Extr. de l'Essor, IVVI, 1942, pp. 4-44.

(21) AichHorn, A. (1923), «On Education in Training Schools», en O. Fleischmann, P. Kramer y H. Ross (eds.), Delinquency and Child Guidance. Selected Papers by August Aichhorn, Nueva York, International Universities Press, 1964, pp. 15-48. 
HISTORIA DE LA PSIQUIATRÍA

(22) SÉCHEHAYE, M. A., La psychanalyse au service des découragés, Ginebra, Chavannes, 1943.

(23) SÉChehaYe, M. A., «Diagnostics Psychologiques», Supplément de la Revue Suisse de Psychologie et de Psychologie Appliquée, 17, Berna, Hans Huber, 1949.

(24) SÉCHEHAYE, M. A., «Techniques de gratifications en psychotherapie analytique: indications et contre-indications», L'évolution psychiatrique, París, 1960, fasc. 3, pp. 297-342.

(25) SÉchehaye, M. A., «Introduction», en A. Burton (ed.), Psychotherapy of the Psychose, Nueva York, Basic Books, 1961, pp. 3-9.

(26) SÉCHEHAYE, M. A., «The Curative Function of Symbols in a Case of Traumatic Neurosis with Psychotic Reactions», en A. Burton (ed.), Psychotherapy of the Psychoses, Nueva York, Basic Books, 1961, pp. 124-151.

Agradezco a la psicóloga Anna-Rosa Cabello Blanco su inestimable ayuda en la localización y versión de textos en francés, y las misivas intercambiadas con sujetos e instituciones suizas.

* Francisco Balbuena Rivera, Psicólogo, Departamento de Psicología Clínica, Experimental y Social, Universidad de Huelva.

Correspondencia: Francisco Balbuena Rivera, C/ Gólgota, nº 8, 2-D 41007 -Sevilla; balbuena@uhu.es

** Fecha de recepción: 1-XI-2008 (aceptado el 15-XI-2008). 